\title{
Balancing patient-centered care and evidence-based medicine in patients needing coronary revascularization
}

Fraser D. Rubens, MD, MSc, FACS, FRCSC, ${ }^{\mathrm{a}}$ Alice Virani, MA (Oxon), MS, MPH, PhD, ${ }^{\mathrm{b}}$

Megan Coylewright, MD, MPH, ${ }^{\mathrm{c}}$ Janarthanan Sathananthan, BHB, MBChB, MPH, FRACP, ${ }^{\mathrm{d}}$ and David Wood, MD, FRCPC, FACC, FESC ${ }^{\mathrm{d}}$

Video clip is available online.

\section{CASE DESCRIPTION}

A 62-year-old woman with CCS Class 2 angina on medical therapy was referred for invasive cardiac catheterization. Her only cardiovascular risk factors were diabetes and a body mass index of 32. Left heart catheterization demonstrated triple vessel disease (TVD), including significant stenosis of the left main and an intermediate SYNTAX score of 30. Left ventricular angiography revealed an ejection fraction of $45 \%$ with anteroapical hypokinesis. At the completion of the procedure, the interventional cardiologist recommended elective coronary artery bypass graft surgery. The patient reported being the primary caregiver for her partner, who has significant disabilities, and expressed the desire to proceed with ad hoc multivessel percutaneous coronary intervention (PCI) instead.

\section{DISCUSSION}

Doing the "right thing" in medicine is often difficult, as patient decisions are complex and informed by a multitude of sometimes competing factors. There is evidence supporting what might be in this patient's best interest from a medical standpoint. In this regard, some may argue that this patient should be referred for surgery to provide the best survival outcome, based on the coronary anatomy, the left ventricular dysfunction, and the presence of diabetes. ${ }^{1,2}$

\footnotetext{
From the a Division of Cardiac Surgery, University of Ottawa Heart Institute, Ottawa, Ontario, Canada; ${ }^{\mathrm{b}}$ Department of Medical Genetics, University of British Columbia, Vancouver, British Columbia, Canada; ${ }^{c}$ Division of Cardiology, Geisel School of Medicine, Dartmouth-Hitchcock Heart and Vascular Center, Hanover, $\mathrm{NH}$; and ${ }^{\mathrm{d}}$ Division of Cardiology, University of British Columbia, Vancouver, British Columbia, Canada.

Received for publication Feb 16, 2021; revisions received March 24, 2021; accepted for publication March 25, 2021; available ahead of print April 16, 2021.

Address for reprints: Fraser D. Rubens, MD, MSc, FACS, FRCSC, Division of Cardiac Surgery, University of Ottawa Heart Institute, 40 Ruskin St, Ottawa, Ontario, Canada K1Y 4W7 (E-mail: frubens@ottawaheart.ca).

J Thorac Cardiovasc Surg 2022;164:1903-6

$0022-5223 / \$ 36.00$

Copyright (c) 2021 by The American Association for Thoracic Surgery

https://doi.org/10.1016/j.jtcvs.2021.03.116
}

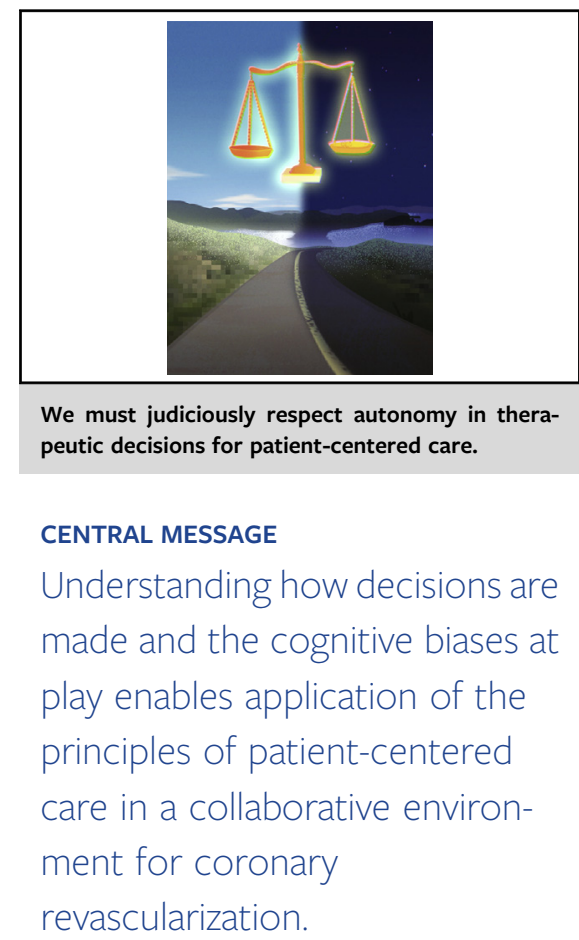

See Commentaries on pages 1907 and 1908.

However, in light of the patient's expressed wishes, would it be appropriate to consider an ad hoc multivessel PCI? In such situations, how do we support patients to exercise their full autonomy and make decisions in their best interest? Does this patient need to see a cardiovascular surgeon before she can make a fully considered and truly informed decision?

The ethical complexity in this case relates to balancing the principles of beneficence and nonmaleficence while respecting patient autonomy. The case also illustrates the opportunity to take a heart team approach while using best practices in shared decision making to partner with the patient in coming to an informed, values-based decision.

\section{Evidence-Based Medicine Versus Patient-Centered Care in the Era of Ad Hoc PCI}

Many aspects of medical care prioritize the concepts of evidence-based medicine (EBM). ${ }^{3}$ This process of decision making involves combining the best available evidence from systematic research with clinician expertise as it 
relates to the medical aspects of an individual patient. The key limitation of EBM is that it fails to incorporate the patient's perspectives and beliefs into the decision at hand. In an era when patient autonomy is considered paramount, the use of guidelines irrespective of patient values may be paternalistic and disrespectful. This highlights the need for greater recognition of the centrality of patients' values and preferences in decision making, understanding that patients bring their own expertise to the contextualization of the potential benefits and harms of the available choices. This reflects the foundation of patient-centered care, which has been embraced by most institutions, echoed by the universal adoption of this terminology in mission and vision statements.

In the present case, the patient indicated a preference not only to have stenting as opposed to surgery, but also to have it done immediately. We agree that ad hoc PCI has a role in cardiovascular care with appropriate indications; however, in complex situations where the available treatment options can only be understood after the anatomy is known, informed consent prior to a diagnostic catheterization will not adequately prepare the patient to participate in shared decision making. Key stakeholders with additional information to inform the decision making not often present during informed consent include the referring provider, a cardiac surgeon, and often the patient's family and friends. Although there may be a benefit in terms of avoiding the inconvenience of a second procedure, this does not negate the importance of integrating the input of these key stakeholders in the shared decision making discussions.

\section{Cognitive Biases in Patient Decision Making}

To provide optimal care for patients undergoing challenging revascularization, we must understand the fundamentals of decision making and integrate these principles into a robust approach to collaborating and communicating in a transparent manner. Patient decisions regarding therapy should be respected as long as the patient has the capacity to make that decision. Capacity is demonstrated by an appreciation of the options (including respective risks, benefits, and limitations), the implications of a decision as they relate directly to themselves, the values associated with the decision (eg, value of quality vs quantity of life), and the consistency of the decision over time. In general, we assume that adults presenting for healthcare have the capacity to make decisions, and we do not intervene in this process unless they overtly demonstrate a lack of capacity (eg, due to cognitive decline) or their capacity is called into question by choices that we perceive to be not in their best interest.

In addition, to ensure their autonomy is respected such that they can make an informed choice, a decision should be not only informed, but also free from coercion, undue influence, or bias.
Patient decisions may be subject to 3 key cognitive biases. First, patients may give disproportionate weight to securing benefits and avoiding harm in the present as opposed to the more distant future, a bias termed "focusing effect aversion." ${ }^{4}$ This is the premise of the Prospect Theory: patients tend to overestimate their utilities for gains and underestimate their utilities for losses. As a result, they inaccurately project their future outcome and may make key decisions depending on how options are framed. For example, radiotherapy of brain tumors, unlike coronary stenting, carries a fairly high risk of early side effects, and thus it is less surprising when patients opt for surgery when presented with that choice. By the same analogy, presentation of options in coronary revascularization biased to reflect early complications of surgery will tilt the choice toward stenting. Clinicians also may unknowingly use language that augments this bias. As an example, framing the discussion with the words "risk versus benefit" may lead the patient to perceive that the risk outlined may or may not occur while the benefit is more certain. This is the rationale supporting the use of "harms versus benefits" as an alternative expression. ${ }^{5}$

The second bias is the availability heuristic. ${ }^{6}$ Patients are influenced by the most recent event in memory, which may include, for example, a discussion of stenting by the interventionalist while the patient is still on the table. The dialog of a surgical option at a later setting may have very little effect in dissuading the patient to follow a different course.

The final bias influencing patient decision making is forecasting error, in which patients have difficulty envisioning their quality of life when recovering from a proposed procedure. ${ }^{7}$ They may decline therapies based on errors, which could include focusing on loss rather than what remains the same, not taking into account their ability to cope with new challenges, and having little insight into how their values may shift.

\section{Shared Decision Making}

Professional guidelines recommend a shared decision making (SDM) approach for patients requiring revascularization, yet there is little direction on how to implement such an approach. ${ }^{8,9} \mathrm{SDM}$ is a bidirectional exchange of information between clinicians and patients (and possibly their families), distinct from the one-way stream of information in traditional patient education or informed consent. ${ }^{10}$ One approach to promoting an SDM process involves the use of patient decision aids, evidence-based tools that may help patients make informed choices about revascularization based on their values and preferences. ${ }^{11}$ This may be of particular value in the challenging area of transaortic valve replacement in low-risk patients to facilitate implementation of best practices, ensuring incorporation of patient goals and preferences into final decision making to improve patient outcomes. ${ }^{12}$ 
There are various barriers to SDM in daily practice. Clinicians need to improve their skillsets and attitudes to distinguish SDM from patient education. ${ }^{12}$ Furthermore, patients may by challenged by literacy and numeracy issues that make communication regarding preference-sensitive decisions difficult without well-designed tools to bridge the gaps between clinician framing and patient needs. Finally, from a system perspective, underlying structural inequities in medicine, resulting in a frequent lack of racial or gender concordance between patients and clinicians, may impact the clinical exchange, limiting expression of the patients' values and preferences. These issues are exacerbated in an "ad hoc" scenario in which the patient is sedated and supine on a procedure table, where power differentials may become particularly problematic.

\section{Role of Interdisciplinary Discussions}

Specialty bias may significantly influence treatment recommendations. This may be particularly manifest when there is equipoise in terms of the outcomes with surgical and nonsurgical approaches, such as in the management of high-risk prostate cancer, where urologists and urologic oncologists each advocate their approach as the best. ${ }^{13}$ The degree of bias in practice patterns also may vary broadly, as demonstrated in Canada by the heterogeneity of the PCI/coronary artery bypass grafting ratio not just within provinces, but also between provinces. ${ }^{14-16}$ Attention to and scrutiny of recommendations are warranted when these conflicts and biases cannot be adequately managed, as they may exert undue influence and discourage free and informed consent.

The COVID-19 pandemic has provided an opportunity to examine priorities in care delivery, with virtual platforms offering new confidence that interdisciplinary teamwork can be optimized. The heart team concept should be a foundation of cardiovascular organizations, and the discussion process should not be limited to once weekly rounds. Virtual meeting platforms are now integrated into many aspects of care, and we are becoming more facile in their use. Medical teams can now quickly put together not just 2 people, but many interested parties instantaneously, including noninterventionalists, to promote robust decisions that are accountable, transparent, and designed to mitigate any perception of bias or conflict while incorporating patient values and preferences. The present case is the ideal scenario in which this might be applicable.

How can we approach SDM in an ethically justifiable manner to best benefit the health interests of our patients? SDM in cases with equipoise includes maximizing steps to make sure the patient is well informed without the stressors of cognitive bias. Applying what we have learned about how patients approach decision making while incorporating patient goals and preferences in revascularization can promote positive health changes. We need to listen to patients with empathy, considering that if we can truly understand their perspective, we may be in a better place to help them better understand how their decision may in fact jeopardize or enhance the goal that they seek. In the present case, this patient's fear may range from adequate coverage for her caregiver responsibilities to personal concerns about the difficulty of recovery for her own health. Exploring the patient's goals of treatment may help identify which option is most likely to help her attain those goals, as well as help ensure that relevant social supports are explored and offered.

What do you do if you believe a patient is not making a decision that is in their best interest, despite these approaches?

A fundamental tenet of modern medicine is respect for a competent patient's choice, even if we do not agree with it. For example, the patient with curable breast cancer who chooses to use naturopathic medicine rather than chemotherapy and radiation is not acting irrationally as long as she has the capacity to make the decision and the decision is informed by her unique values and wishes. If we call a decision irrational, it might be perceived that we are disagreeing with the values by which the patient defines their own good, rather than outlining that the patient's choice will fail to promote those aims and goals. We must remind ourselves of our fiduciary responsibility: the obligation one party has in relationship with another party to act on the latter's behalf and best interest. In medicine, we are governed by our duty to provide for our patients' well-being, which might include attempts to protect them from the harmful consequences of their choices when these choices will not lead to their stated goal. However, these attempts should not go so far as to override informed decisions, if these decisions are within a clinically acceptable range. In the case presented, there may be a survival benefit of surgery, ${ }^{17,18}$ but who are we to say that this outweighs the importance to this patient of reducing the risk of short-term surgical complications and returning home quickly, as she has expressed.

If a patient chooses a path that the provider does not believe is in their best interest, does the surgeon/interventionalist have the right to refuse? According to Brock and Wartman, "shared decision-making respects the patient's right to self-determination but does not require that the patient's preferences be simply accepted when they are irrational." ${ }^{19}$ We have all dealt with who have sought an intervention that was deemed unnecessary and entailed excessive risk and have appropriately refused. On the other hand, if all of the aforementioned steps have been taken with healthy robust processes in place to minimize bias in the decision, and the patient still wishes PCI, for example, then it would be appropriate to proceed.

In summary, we need to reframe our thinking such that we consider whether a patient's decision to be reasonable 


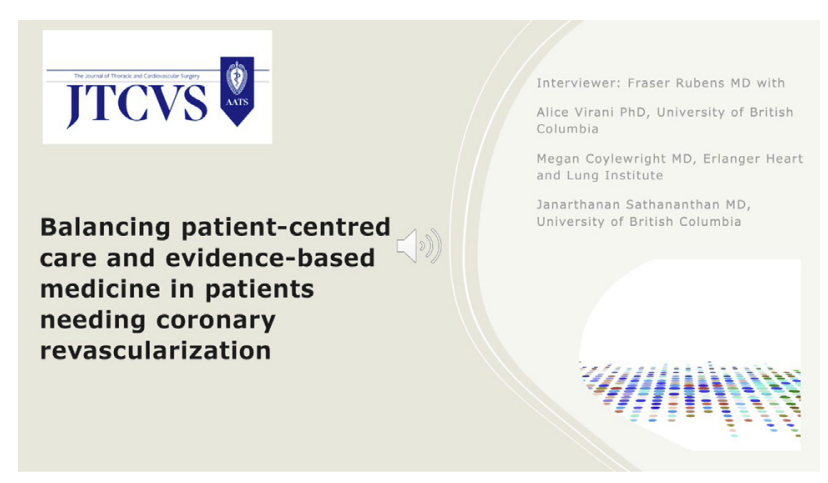

VIDEO 1. Interview of Drs Virani, Coylewright, and Sathananthan by the lead author Dr Rubens highlighting the key ethical and clinical considerations in this case. Video available at: https://www.jtcvs.org/article/ S0022-5223(21)00696-6/fulltext.

even if we do not consider it in to be their best interest. Promotion of patient autonomy entails recognition that in circumstances where clinical uncertainty and equipoise exist, we allow competent patients to work through the harms and benefits of each option and apply their values to make a decision that is right for them. In this scenario, it is essential to make sure that communications with the patient are carefully managed so that the long-term health benefits are integrated into this discussion. Beneficent persuasion reflects our duty to encourage patients to engage in healthy behaviors. We are not advocating coercion or manipulation, which violate the patient's rights, but we must ensure strategies and mechanisms to best promote informed decision making (Video 1).

\section{CONCLUSIONS}

Although cardiac surgeons and cardiologists enter medicine with a commitment to do the right thing, we are often beset by challenges that make patient decisions complex. We have robust guideline-based recommendations promoting EBM. Including the patient voice through such processes as SDM will ensure an ongoing commitment to patient-centered care, respecting patient autonomy and optimizing outcomes by matching patient goals with state-of-the-art choices in coronary revascularization.

\section{Conflict of Interest Statement}

The authors reported no conflicts of interest.

The Journal policy requires editors and reviewers to disclose conflicts of interest and to decline handling or reviewing manuscripts for which they may have a conflict of interest. The editors and reviewers of this article have no conflicts of interest.

\section{References}

1. Neumann FJ, Sousa-Uva M, Ahlsson A, Alfonso F, Banning AP, Benedetto U, et al. 2018 ESC/EACTS guidelines on myocardial revascularization. Eur Heart J. 2019;40:87-165.

2. Patel MR, Calhoon JH, Dehmer GJ, Grantham JA, Maddox TM, Maron DJ, et al ACC/AATS/AHA/ASE/ASNC/SCAI/SCCT/STS 2017 appropriate use criteria for coronary revascularization in patients with stable ischemic heart disease: a report of the American College of Cardiology appropriate use criteria task force, American Association for Thoracic Surgery, American Heart Association, American Society of Echocardiography, American Society of Nuclear Cardiology, Society for Cardiovascular Angiography and Interventions, Society of Cardiovascular Computed Tomography, and Society of Thoracic Surgeons. J Am Coll Cardiol. 2017;69:2212-41.

3. Sackett DL, Rosenberg WM, Gray JA, Haynes RB, Richardson WS. Evidence based medicine: what it is and what it isn't. BMJ. 1996;312:71-2.

4. Kahneman D, Tversky A. Prospect theory: an analysis of decision under risk. Econometrica. 1979; 47:263-92.

5. Morgan DJ, Scherer LD, Korenstein D. Improving physician communication about treatment decisions: reconsideration of "risks vs benefits" JAMA. 2020; 324:937-8.

6. MacLeod C, Campbell L. Memory accessibility and probability judgments: an experimental evaluation of the availability heuristic. J Pers Soc Psychol. 1992; 63:890-902.

7. Halpern J, Arnold RM. Affective forecasting: an unrecognized challenge in making serious health decisions. J Gen Intern Med. 2008;23:1708-12.

8. Hess EP, Coylewright M, Frosch DL, Shah ND. Implementation of shared decision making in cardiovascular care: past, present, and future. Circ Cardiovasc Qual Outcomes. 2014;7:797-803.

9. Levine GN, Bates ER, Blankenship JC, Bailey SR, Bittl JA, Cercek B, et al. 2011 ACCF/AHA/SCAI guideline for percutaneous coronary intervention: a report of the American College of Cardiology Foundation/American Heart Association task force on practice guidelines and the Society for Cardiovascular Angiography and Interventions. J Am Coll Cardiol. 2011;58:e44-122.

10. National Quality Forum. National Quality Partners Playbook: Shared Decision Making in Healthcare; 2018. Available at: https://store.qualityforum.org/ products/national-quality-partners-playbook $\%$ E2\% $\% 4 \%$ A2-shared-decisionmaking. Accessed March 24, 2021.

11. Stacey D, Légaré F, Lewis K, Barry MJ, Bennett CL, Eden KB, et al. Decision aids for people facing health treatment or screening decisions. Cochrane Database Syst Rev. 2017;4:CD001431.

12. Coylewright M, Dick S, Zmolek B, Askelin J, Hawkins E, Branda M, et al. PCI choice decision aid for stable coronary artery disease: a randomized trial. Circ Cardiovasc Qual Outcomes. 2016;9:767-76.

13. Kishan AU, Duchesne G, Wang PC, Rwigema JM, Saigal C, Rettig M, et al. Does specialty bias trump evidence in the management of high-risk prostate cancer? Am J Clin Oncol. 2018;41:549-57.

14. Tu JV, Ko DT, Guo H, Richards JA, Walton N, Natarajan MK, et al. Determinants of variations in coronary revascularization practices. CMAJ. 2012;184:179-86.

15. Ouzounian M, Ghali W, Yip AM, Buth KJ, Humphries K, Stukel TA, et al. De terminants of percutaneous coronary intervention vs coronary artery bypass grafting: an interprovincial comparison. Can J Cardiol. 2013;29:1454-61.

16. Schwalm JDR, Wijeysundera HC, Tu JV, Guo H, Kingsbury KJ, Natarajan MK Influence of coronary anatomy and SYNTAX score on the variations in revascularization strategies for patients with multivessel disease. Can J Cardiol. 2014; 30:1155-61.

17. Krishnaswamy A, Kapadia SR. Minimizing stroke and mortality risks in coronary revascularization. J Am Coll Cardiol. 2018;72:399-401.

18. Tam DY, Dharma C, Rocha R, Farkouh ME, Abdel-Qadir H, Sun LY, et al. Longterm survival after surgical or percutaneous revascularization in patients with diabetes and multivessel coronary disease. J Am Coll Cardiol. 2020;76:1153-64.

19. Brock DW, Wartman SA. When competent patients make irrational choices. N Engl J Med. 1990;322:1595-9.

Key Words: patient-centered care, coronary artery bypass grafting, percutaneous coronary intervention, decision aids, ethics 